\title{
"This is new and dynamic, and we are going to have to learn together"
}

\author{
The Metropolitan Police chief in charge of counterterrorism tells Richard Vize that the Prevent \\ strategy is about safeguarding, not surveillance
}

Richard Vize freelance journalist

London

The shift in the terrorist threat from networks to lone attacks has put mental health and the protection of vulnerable people at the centre of the UK's counterterrorism strategy.

Metropolitan Police assistant commissioner Mark Rowley, the national lead on counterterrorism policing, tells The BMJ that the involvement of the NHS in Prevent-the part of the counterterrorism plan aimed at stopping people becoming terrorists—is "massively important, more important than it's ever been."

He says, "We have wrestled with terrorism in the UK for at least 50 years, but for most of that time-whether it was the IRA or $\mathrm{Al}$ Qaeda - there were secret networks planning attacks, and the sort of people they recruited had to be highly trustworthy and reliable."

Now, terrorist groups try to incite people through propaganda on the internet and social media to carry out attacks: "Part of that has led them to-sometimes accidentally, sometimes very deliberately - trying to exploit vulnerable people."

Rowley claims that, of the people involved in the 13 attacks that the security services say they have foiled since 2013 , "a disproportionate number of them do have mental health issues." He would not specify a number.

Rowley emphasises that any suggestion that mental illness causes terrorism is "complete nonsense." Instead, the concern of the police is that people with vulnerable mental health are susceptible to being targeted: "If part of the terrorist methodology is to prey on the vulnerable and trying to exploit them and to radicalise them to commit acts of violence, then it stands to reason that there will be people with certain mental health conditions who will be ... susceptible to that.

"Radicalising and inciting someone who is vulnerable to go and carry out some ghastly attack seems to be part of their tactics, and that has brought in a whole load of vulnerability issues, including mental health, that we now have to wrestle with."
Rowley is adamant that collaboration between the NHS and the police is about safeguarding vulnerable people, not surveillance to identify criminals. "If we allow a rumour to grow that this is about health as surveillance, then that is wrong, and damaging to health professionals, police, community relations, the Prevent programme, everything. That is not what we are about. This is about safeguarding and prevention.”

The analogue he returns to constantly is child protection, where multiagency working to keep vulnerable children from harm is routine: "We are used to safeguarding vulnerable people across different agencies-young people who are at risk of physical or sexual abuse, trafficking, gangs. This has a lot of commonality with that."

\section{Ensuring a preventive strategy}

Rowley points out that a clinician can try to deal with people's mental health issues but cannot protect them from the influence of others trying to radicalise them. That is why clinicians need to work with the police.

"One thing in talking to mental health professionals that has struck me is their understandable pride in their expertise in managing risk. I can't possibly dispute that. The issue here that is different is: if some of the risk is not simply about the mental health condition but is about somebody else revving them up and trying to exploit it, then however good the mental health professional is, the mental health team on its own is probably insufficient.

"That's why we have to work together, and it requires a bit more trust and collaboration between us . . . If we don't intervene soon enough, that victim becomes a very serious perpetrator, and if they are about to go and kill people we then have to intervene with a different hat on and prosecute people.

"If we are willing to share information and work together then we can keep this as a preventive response, which is what we all 
believe in. Waiting for people to try to commit serious offences then putting them in prison for ever is not as elegant a solution."

Rowley says that the Prevent strategy in the NHS has "got scope to improve-the understandable caution of health professionals in sharing information can mean that sometimes we are not collaborating as much as we could be."

Clinicians are frustrated at the unwillingness of the Home Office and police to share information, such as providing feedback on the outcomes of their referrals of patients and publishing data to ensure that NHS involvement in Prevent is based on evidence.

Rowley describes accusations of a lack of transparency as "a fair challenge," adding that in most cases there is no reason why the police should not provide feedback on what has happened after a referral, just as they would share information on a suspected case of child abuse with other agencies: "We can absolutely do that ... We obviously need to do more. I will speak to my colleagues about that."

\section{Research results}

The results of two research projects, due to be published in the coming months, should illuminate this complex area.

The first is a review commissioned by the Home Office of three mental health pilot hubs set up a year ago in the West Midlands, Manchester, and London, where mental health practitioners are embedded in regional counterterrorism units. The pilots aim to improve understanding of connections between mental health and vulnerability to radicalisation, and to identify how specialist mental health teams should work with counterterrorism police to reduce risk to the public and keep vulnerable people out of the criminal justice system.

The second study, led by the clinical psychologist Nicola Fowler at Birmingham and Solihull Mental Health Foundation Trust, is looking in detail at connections between mental health vulnerability and the risks of becoming involved in terrorism.

Research is racing to catch up with the change in terrorists' tactics to inciting lone attacks, which became apparent around two years ago. ${ }^{1}$ Rowley says, "We are still learning the best way to deal with it.

"With such a new and changing field it is not surprising that we haven't got 20 years of peer reviews and published research, because the IRA and Al Qaeda didn't work like this. That's why we need a constructive approach between the two professions.

"This is new and dynamic, and we are going to have to learn together."

Competing interests: I have read and understood BMJ's policy on declaration of interests and have no relevant interests to declare. Commissioning and peer review: Commissioned; not peer reviewed.

Bhui K, James A, Wessely S. Mental illness and terrorism. BMJ 2016;354:14869. doi:10.1136/bmj.i4869.27624715

Published by the BMJ Publishing Group Limited. For permission to use (where not already granted under a licence) please go to http://group.bmj.com/group/rights-licensing/ permissions 